
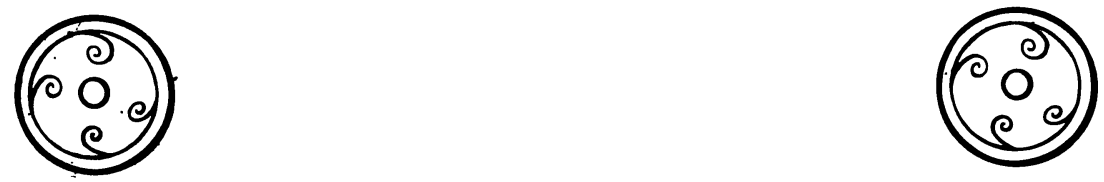

\title{
Items of Interest
}

REPORT OF SCHOLARLY TRIP TO CHINA

In March, 1980, Noel Barnard and Cheung Kwongyue of the Australian National University made a scholarly trip to the Peoples' Republic of China, visiting Research Institutes, Museums, and Universities in Canton, Peking, Sian, Cheng-chou, Hangchou, Shanghai, and Ch'ang-sha. A detailed report of their trip, and their further activities in the ensuing months, titled: Studies in Chinese Archae.ology in 1980 -- Reports on Visits to Mainland China, Taiwan, and the USA; Participation in Conferences in these Countries; and some Notes and Impressions, privately published and to appear in 1981 (approx. 200 pp., 20 Figures, Appendixes, Indexes, A4 size, stiff paper covers). Scholars in our field will find of great interest and value the comprehensive lists of authors and papers presented at recent conferences in Canton, Ch'eng-tu, Nankang (Taipei), the Metropolitan Museum Symposium, and the Berkeley Workshop (for which, see Early China 5); the lists of academics, archaeologists, technicians, and students (and their scholarly affiliations) who are specializing in pre-Han studies in China; and the cross-indexing of all this data. An edition of 200 copies only is planned. The work may be ordered from Noel Barnard, Department of Far Eastern History, Australian National University, GPO Box 4, Canberra ACT 2600 Australia.

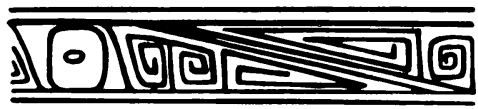

BRONZE AGE TALKS

The following lectures were given at the Santa Barbara Museum of Art on May 10 and 17, 1981, when "The Great Bronze Age of China" was exhibited in Los Angeles.

"The Great Bronze Age of China"

Susan Shin-tsu Tai, Assistant Curator of Oriental Art
Susan Tai discussed the significance of : tant bronzes and jades from the earliest peric China, the Shang and Chou dynasties (ca. 1500 Recent archaeological excavations are respons: for these and other recent finds, including $a$ of larger-than-life-size terracotta horses anc diers from the Mausoleum of the first emperor Ch'in, who died in 210 B.C.

"Sixty-Four Ancient Chinese Bells"

Victoria Quan, Professor at the Shanghai Const tory for 28 years and currently teaching UCSB

Victoria Quan spoke on the set of bells , from 433 B.C., excavated in 1978 in the Hubei province. These bells form the most complete best-preserved set ever found. They are prec dated, and have remained untouched for over 2 , years. Of interest is the fact that these are first ancient bells found with musical notatic scribed on them. Although more than 2,000 yei old, these notations indicate use then of the tuning system in use today--the seven-note sci with sharps and flats. Thus is has been poss: transcribe the notations and tapes of the resi music will be played.

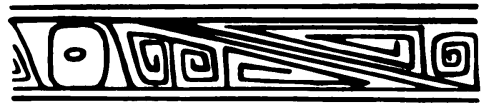

FREER EXHIBITS ANCIENT CHINESE JADE

The finest pieces of early jade from the millennium B.C. through the third century A.D. the collection of the Smithsonian's Freer Gal. of Art were placed on exhibition beginning Thi Sept. 4, 1980.

Among the more than 130 objects gathered the Freer collection for the exhibition, "Anc. 
Chinese Jade," are several artifacts now thought to date from the prehistoric era of the Neolithic or New Stone Age. The new dating is based on finds in recent archaeological excavations in China.

Jade has been worked in China for more than 4,000 years. A variety of semi-precious hardstones collectively known as jade (yü) were fashioned into ritual objects and personal ornaments. Only two of these hardstones, nephrite and jadeite, are now recognized as true jade.

Only nephrite was available to the ancient Chinese. It was imported eastward over immense distances from the riverbeds of Khotan and Tarkand in what is now the northwest region of Sinkiang. Some also may have been brought from the Lake Baikal region of eastern Siberia.

Because of its great hardness, nephrite is not actually "carved" in the strict sense of the word, but worn away by abrasion. Objects in the Freer exhibition were laboriously worked by grinding moistened quartz sand into them with simple tools--drills, saws and points made of wood, bone, bamboo or cord.

Early jade objects come in various shapes, some of them modeled on the utilitarian stone tools of the Neolithic period, such as the ax $(\mathrm{fu})$, adze (ch'an), trapezoidal harvesting knife (hu) and chisel (kuei).

Neolithic sites of east and southeast coastal China have revealed disks ( $p i$ ), rings (huan and yüan) bracelets (cho), semi-circular ornaments (huang), handles (ping) and animal amulets.

In the Shang period (ca. 1523-1027 B.C.), the jade repertoire was augmented by shapes based on bronze prototypes such as spearheads and dagger axes (ko). The scepter-like blade (chang) and the squared cylindrical tube (tsung) also rose to prominence in the late Shang period, al though their origins may actually be Neolithic. Examples of many of the shapes are included in the Freer exhibition.

On a few early jades there appear emblematic motifs incised using a single-line technique. Designs similar to some of these emblems also occur on large pottery jars excavated from coastal Neolithic sites and others on stone implements of the Lung-shan culture (late third-early second millennium B.C.). The similarities suggest that the jades may also belong to a Neolithic context rather than the Western Chou period (ca. 1027-771 B.C.) to which they have traditionally been ascribed.

Surface decorations that appear on jades of the Chinese Bronze Age (Shang through Han periods ca. 1523 B.C.-A.D. 220) are clearly related in form and motif to the repertoire of bronze decor, sharing filler patterns of spirals and meanders as well as mask-1ike faces and geometric designs.

Improved techniques of jade working in the Eastern Chou period (770-221 B.C.), such as the use of metal rotary tools, stimulated vigorous developments in the decoration of jades. Jades of this period, such as the tiger-shaped plaque and

the elaborate necklace in the exhibition, display more complicated shapes as well as elaborate surface designs in relief, intaglio and openwork. Often, they are polished to a very high gloss.

In the Chou period, jades had come to play an important role in funerary rituals because they were thought to prevent physical decay and to aid in summoning the soul back to the body.

During the Han period (206 B.C.-A.D. 220), jade was increasingly used to make secular objects for refined enjoyment. Furthermore, the focus of interest in jade-working shifted decisively toward the sculptural mode and away from the essentially linear aesthetic which had dominated the craft up to that time.

While certain types of ritual jades, such as pi discs and personal ornaments, continued to be made, they yielded priority to figures and animals executed in the round. Thus, the ancient period of jade-working came to a close, to be followed by developments different in intent and result.

The exhibition on display for an indefinite period, was selected and organized by Julia K. Murray of the Freer's curatorial staff.

A leaflet explaining the history and development of Chinese jade is available to visitors at no cost.

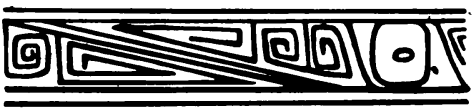

CHINESE RELICS AT INDIANAPOLIS MUSEUM OF ART FROM THE COLLECTION OF DR. RALPH MARCOVE

For more than a decade, Dr. Marcove focused his energies and resources on the arts of China. His collection, which of course reflects his interests, is not confined to one medium or one time period. Throughout his quest for art, Dr. Marcove has had the good fortune to find guidance and help from many experts in the field, including Dr. Yutaka Mino of the IMA. The selected Chinese relics from the Marcove collection, 82 pieces from the Shang Dynasty to the Ch'ing Dynasty, cover such diverse media as bamboo, bronze, ceramic, jade and stone. A fully illustrated catalogue, prepared by the Oriental Art Department was prepared. The exhibition was on view March 3 April 12, 1981.

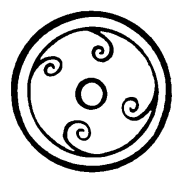

